\title{
Elementos-traço em dois latossolos após aplicações anuais de lodo de esgoto por treze anos ${ }^{1}$
}

\section{Trace elements in two Oxisols after annual application of sewage sludge for thirteen years}

\author{
Maurício Gomes de Andrade ${ }^{2 *}$; André Suêldo Tavares de Lima \\ Wanderley José de Melo ; Eder José dos Santos ${ }^{5}$; Amanda Beatriz Herrmann ${ }^{5}$
}

\begin{abstract}
Resumo
O objetivo deste experimento foi avaliar os teores e o efeito cumulativo dos elementos-traço (ETs) arsênio, bário, cádmio, cromo, cobre, mercúrio, molibdênio, níquel, chumbo, selênio e zinco, da resolução 375 do CONAMA, após 13 anos consecutivos de aplicação de lodo de esgoto (LE) em dois Latossolos (Latossolo Vermelho eutroférrico - LVef e Latossolo Vermelho distrófico - LVd). O experimento foi realizado no campo sob cultivo de milho e constou de quatro tratamentos $(0,5,10$ e $20 \mathrm{t}$ de LE ha ${ }^{-1}$, base seca) e cinco repetições, em delineamento experimental em blocos ao acaso. Amostras dos insumos agrícolas (calcário, superfosfato simples e cloreto de potássio) aplicados aos solos, LE, solos e materiais de referência certificados foram digeridos conforme método USEPA 3051A e os elementos químicos foram quantificados por ICP-OES. Os teores dos ETs encontrados nos insumos agrícolas não devem causar impacto ambiental imediato. Os maiores teores dos ETs foram encontrados no LVef e ainda não atingiram o valor de investigação (VI) agrícola (o mais restritivo) segundo os critérios da resolução 420/2009 do CONAMA. Persistindo a atual taxa de aplicação de LE e teores médios dos ETs incorporados aos solos, prevê-se que $\mathrm{Ba}, \mathrm{Cd}, \mathrm{Cr}, \mathrm{Cu}, \mathrm{Ni}$ e $\mathrm{Zn}$ serão os primeiros elementos químicos a atingirem o VI no LVef.

Palavras-chave: Solos tropicais, metais pesados, contaminação do solo, fertilizantes, poluição do solo, resíduos urbanos
\end{abstract}

\begin{abstract}
This experiment aim was to evaluate the contamination of the trace elements (TE) arsenic, barium, cadmium, chromium, copper, mercury, molybdenum, nickel, lead, selenium, and zinc considered in the CONAMA resolution 375 after 13 years long using sewage sludge (SS) as fertilizer in two soils: an Eutroferric Clayed Red Latosol (Rhodic Eutrudox - RE) and a Dystrophic Red Latosol (Typic Haplorthox - TH). Experiment in the field under maize cultivation had four treatments $(0,5,10$, and $20 \mathrm{t}$ of SS ha ${ }^{-1}$, dry weight), five replications and an experimental design in randomized blocks. The agrochemicals (dolomitic limestone, single superphosphate, and potassium chloride), SS, soils, and the certified reference materials were digested according to the USEPA 3051A method and the chemical
\end{abstract}

\footnotetext{
${ }^{1}$ Parte da tese de doutorado do primeiro autor.

2 Prof. do Dept ${ }^{\circ}$ Acadêmico de Química e Biologia da Universidade Tecnológica Federal do Paraná, UTFPR, Curitiba, PR. E-mail: mandrade@utfpr.edu.br

${ }^{3}$ Prof. do Instituto Federal de Educação, Ciência e Tecnologia de Roraima, IFRR, Campus Amajari, RR. E-mail: andresueldo@, ig.com.br

${ }^{4}$ Prof. Titular do Dept ${ }^{\circ}$ de Tecnologia da Universidade Estadual Paulista, UNESP, Faculdade de Ciências Agrárias e Veterinárias, Jaboticabal, SP. E-mail: wymelo@gmail.com

5 Pesquisadores do Instituto de Tecnologia do Paraná, TECPAR, Curitiba, PR. E-mail: eder@tecpar.br; amandabh@tecpar.br

* Autor para correspondência
} 
elements were quantified by ICP OES. The TE contents found in the agrochemicals used should not cause immediate environmental impact. The higher TE values were found in the RE and they did not reach the agricultural (more stringent) Investigation Level (IL) yet, according to 420 CONAMA resolution. Persisting the actual SS fertilization amount applied in the soil and the TE concentration in the $\mathrm{SS}$ is foreseen that $\mathrm{Ba}, \mathrm{Cd}, \mathrm{Cr}, \mathrm{Cu}, \mathrm{Ni}$, and $\mathrm{Zn}$ will be the first elements to reach the IL in the RE.

Key words: Tropical soils, heavy metals, soil contamination, fertilizers, soil pollution, urban residues

\section{Introdução}

Os elementos-traço (ETs) encontram-se naturalmente em solos e em sistemas aquáticos superficiais e subterrâneos, mesmo que não haja interferência antrópica. $\mathrm{O}$ aumento da concentração dos ETs no meio ambiente pode ocorrer tanto em razão de processos ambientais (atividades vulcânicas) como atividades antrópicas (atividades industriais, domésticas e agrícolas) (ANDRADE, 2011).

Alguns ETs são considerados essenciais às plantas $(\mathrm{Cu}, \mathrm{Mo}, \mathrm{Ni}$ e $\mathrm{Zn})$ e eventualmente à saúde humana ( $\mathrm{Cr}, \mathrm{Cu}$, Se e $\mathrm{Zn}$ ), enquanto outros são considerados tóxicos ( $\mathrm{As}, \mathrm{Ba}, \mathrm{Cd}, \mathrm{Hg}$ e $\mathrm{Pb}$ ). Entretanto, mesmo os essenciais podem, sob condições específicas, causar impactos negativos a ecossistemas terrestres e aquáticos, constituindose, assim, em contaminantes ou poluentes do solo, da água e do ar. Como exemplo, segundo Lemly (2004), uma concentração de 2 a $5 \mu \mathrm{g} \mathrm{L}^{-1}$ de $\mathrm{Se}$ em água é altamente prejudicial à sobrevida de peixes e da vida selvagem como um todo. O Se orgânico dissolvido ou sob formas aniônicas, $\mathrm{Se}$ (IV) e Se (VI) podem se bioacumulados. Na forma orgânica o Se pode substituir o S em aminoácidos e proteínas. Essas últimas são essenciais na transição genética, e alterações ocorridas que podem levar ao desenvolvimento de malformações ocasionadas por mutações genéticas.

A presença dos ETs (As, Ba, Cd, Cr, Cu, Hg, $\mathrm{Mo}, \mathrm{Ni}, \mathrm{Pb}$, Se e $\mathrm{Zn}$ ) em lodo de esgoto (LE) é um dos fatores que pode limitar o uso deste resíduo em solos agrícolas. A resolução 375 (CONAMA, 2006) regulamenta o uso agrícola de $\mathrm{LE}$ em todo território brasileiro. A decisão de diretoria no 195 (CETESB, 2005) dispõe sobre os valores orientadores para solos no Estado de São Paulo. A resolução 420 (CONAMA, 2009) dispõe sobre critérios e valores orientadores de qualidade do solo quanto à presença de substâncias químicas e estabelece diretrizes no gerenciamento ambiental de áreas contaminadas por essas substâncias em decorrência de atividades antrópicas no território brasileiro. Essas diretrizes delimitam os teores máximos de substâncias químicas no resíduo, a aplicação anual e acumulada, assim como a concentração no solo, tendo como objetivo evitar danos ao meio ambiente.

Para que as legislações interpretem os reais fatos da natureza, pesquisas de aplicação contínua de LE por longo prazo, em terras agricultáveis ou não, são necessárias. Muitos de seus efeitos, tais como o enriquecimento da matéria orgânica e principalmente os possíveis elementos químicos tóxicos que se acumulam no solo, evoluem lentamente, são difíceis de prever (BERGKVIST et al., 2003).

A presença destes contaminantes inorgânicos, os ETs, no meio ambiente, pode promover a bioacumulação e/ou a biomagnificação na cadeia alimentar, gerando distúrbios metabólicos nos seres vivos e transformando baixas concentrações em elevados teores tóxicos para diferentes espécies da biota e para o próprio homem.

Kiekens e Cottenie (1985) relataram que o teor total de ETs presentes em solo não é um bom atributo para se fazer previsões de fitodisponibilidade, porém essa determinação tem por objetivo obter informações sobre o acúmulo total destes elementos ao longo do tempo. Para tanto, esta análise exige que o solo seja digerido com ácidos fortes concentrados $\left(\mathrm{HNO}_{3}, \mathrm{HClO}_{4}\right.$ e $\left.\mathrm{HCl}\right)$ e complementada com $\mathrm{HF}$, que apesar de fraco, atua na dissolução total do 
resíduo silicatado restante. Para efeito ambiental, essa digestão não reflete a total realidade da natureza.

Portanto, a preferência pelo uso de $\mathrm{HNO}_{3}$ isoladamente ou em mistura com outros ácidos, tais como perclórico $\left(\mathrm{HNO}_{3}+\mathrm{HClO}_{4}-5: 1\right)$ ou $\mathrm{HCl}$ (água régia, $\mathrm{HCl}+\mathrm{HNO}_{3}-3: 1$ ), é muito comum para simular o efeito ambiental sobre matrizes como solos, lodos e sedimentos. Seguindo os princípios da química verde, é recomendável a utilização de aparelho de micro-ondas, assim, o uso desse aparelho traz, além da redução do tempo de análise, redução de contaminação, menor quantidade de reagentes e amostra, menor perda de espécies voláteis e maior segurança ao operador (SANDRONI; SMITH, 2002).

O objetivo deste experimento foi avaliar os teores e o efeito cumulativo dos elementos-traço (ETs) citados na resolução 375 do CONAMA (arsênio, bário, cádmio, cromo, cobre, mercúrio, molibdênio, níquel, chumbo, selênio e zinco) após 13 anos consecutivos de aplicação de lodo de esgoto (LE) em dois Latossolos (Latossolo Vermelhos eutroférrico - LVef e Latossolo Vermelho distrófico $-\mathrm{LVd})$.

Tabela 1. Valores médios da composição granulométrica em diferentes camadas de Latossolo Vermelho eutroférrico (LVef) e Latossolo Vermelho distrófico (LVd).

\begin{tabular}{|c|c|c|c|c|c|c|}
\hline \multirow{3}{*}{ Fração } & \multicolumn{3}{|c|}{ Latossolo Vermelho eutroférrico } & \multicolumn{3}{|c|}{ Latossolo Vermelho distrófico } \\
\hline & 0-0,1 m & 0,1-0,2 m & $0,2-0,3 \mathrm{~m}$ & $\mathbf{0 - 0 , 1 ~ m ~}$ & 0,1-0,2 m & $0,2-0,3 \mathrm{~m}$ \\
\hline & \multicolumn{6}{|c|}{---------------------------------------------'-g kg } \\
\hline Argila & 485 & 508 & 525 & 245 & 278 & 285 \\
\hline Silte & 297 & 281 & 273 & 68 & 62 & 63 \\
\hline Areia total & 219 & 212 & 202 & 687 & 661 & 652 \\
\hline Areia grossa & 90 & 86 & 77 & 388 & 349 & 356 \\
\hline Areia fina & 129 & 126 & 125 & 299 & 312 & 296 \\
\hline
\end{tabular}

Fonte: Melo et al. (2004).

\section{Material e Métodos}

As áreas experimentais, um Latossolo Vermelho eutroférrico típico (LVef), textura argilosa, e em um Latossolo Vermelho distrófico típico (LVd), textura média (MELO et al., 2004), destinadas exclusivamente às pesquisas do uso de LE na agricultura, foram instaladas inicialmente em 1997, na Fazenda de Ensino e Pesquisa da Universidade Estadual Paulista/UNESP - Câmpus de Jaboticabal - São Paulo - Brasil. Por 13 anos consecutivos, foi feita uma aplicação de LE nos dois Latossolos. O delineamento experimental foi em blocos casualizados (DBC), com quatro tratamentos e cinco repetições, totalizando 20 unidades experimentais de $60 \mathrm{~m}^{2}$ cada. Este experimento foi realizado no ano agrícola de 2009/2010, portanto 13 anos após sua instalação.

Os Latossolos são solos de material geológico constituído por arenitos do Grupo Bauru, Formação Adamantina, e por basaltos do Grupo São Bento, Formação Serra Geral. É de grande ocorrência na região e em todo o Estado de São Paulo. O clima local é classificado, segundo Köppen, como subtropical de inverno seco (Aw) (VOLPE; CUNHA, 2008). O perfil da composição granulométrica média dos solos utilizados no estudo é encontrado na Tabela 1. 
Os tratamentos: $\mathrm{T} 0=$ testemunha, com fertilização química convencional; T $5, \mathrm{~T} 10 \mathrm{e}$ T 20 (5, 10 e $20 \mathrm{t} \mathrm{ha}^{-1}$ de LE, base seca) foram estabelecidos de modo a fornecer 0 (T 0), 100 ( $\mathrm{T}$ 5), 200 (T 10) e $400 \%$ (T 20) de todo nitrogênio exigido pela cultura do milho, admitindo-se que
1/3 do o nitrogênio contido no LE encontrava-se disponível para as plantas. Amostras de solo de todas as parcelas foram colhidas na profundidade 0-0,20 $\mathrm{m}$ antes do início do ano agrícola de 2010, e seus atributos químicos encontram-se na Tabela 2.

Tabela 2. Atributos químicos do Latossolo Vermelho eutroférrico (LVef) e Latossolo Vermelho distrófico (LVd) antes da instalação do décimo terceiro ano de experimentação.

\begin{tabular}{|c|c|c|c|c|c|c|c|c|c|c|}
\hline Lodo de esgoto & $\mathrm{pH} \mathrm{CaCl}_{2}$ & MO & $P$ resina & $\mathbf{K}$ & $\mathbf{C a}$ & Mg & $\mathbf{H}+\mathbf{A l}$ & SB & CTC & $\mathbf{V}$ \\
\hline t hat $\mathbf{h}^{-1}$ & $0,01 \mathrm{~mol} \mathrm{~L}^{-1}$ & $\mathbf{g} \mathbf{d m}^{-3}$ & $\mathbf{m g ~ d m}{ }^{-3}$ & \multicolumn{6}{|c|}{ - } & $\%$ \\
\hline \multicolumn{11}{|c|}{ 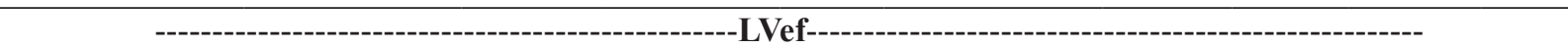 } \\
\hline T 0 & 4,62 & 21,4 & 31,0 & 3,66 & 22,6 & 7,2 & 50,4 & 33,46 & 83,86 & 39,8 \\
\hline T 5 & 4,60 & 24,0 & 34,8 & 3,42 & 24,8 & 7,6 & 56,4 & 35,88 & 92,22 & 39,2 \\
\hline T 10 & 4,74 & 26,0 & 80,8 & 4,16 & 32,2 & 9,0 & 54,8 & 45,36 & 100,16 & 45,2 \\
\hline T 20 & 4,40 & 26,2 & 86,0 & 2,98 & 22,4 & 5,8 & 70,4 & 31,18 & 101,58 & 30,6 \\
\hline \multicolumn{11}{|c|}{ 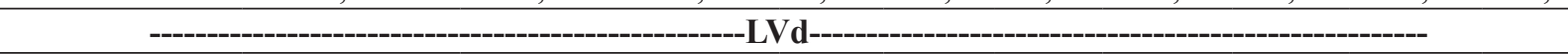 } \\
\hline T 0 & 4,66 & 19,4 & 47,8 & 2,14 & 18,6 & 4,8 & 39,0 & 25,54 & 64,54 & 40,0 \\
\hline T 5 & 4,98 & 19,8 & 55,2 & 2,46 & 24,6 & 6,8 & 32,2 & 33,86 & 66,06 & 51,2 \\
\hline T 10 & 4,84 & 21,2 & 95,6 & 2,50 & 26,2 & 6,2 & 40,0 & 34,90 & 74,90 & 47,0 \\
\hline T 20 & 4,50 & 20,2 & 94,0 & 2,00 & 19,2 & 4,6 & 49,8 & 25,80 & 75,60 & 35,2 \\
\hline
\end{tabular}

MO: matéria orgânica; SB: soma de bases; CTC: capacidade de troca de cátions; V: saturação por bases.

Fonte: Elaboração dos autores.

O LE utilizado no experimento foi obtido junto à Estação de Tratamento de Esgoto da Companhia de Saneamento Básico do Estado de São Paulo (ETE-Sabesp), localizada no município de Barueri. Esse LE é proveniente dos esgotos da grande São Paulo e é constituído por uma mistura de esgotos domiciliares e industriais. Os atributos do potencial agronômico do LE (base seca), conforme anexos II, III e IV da resolução 375 (CONAMA, 2006) foram: $\mathrm{C}_{\text {org }}=246,75 \mathrm{~g} \mathrm{~kg}^{-1}, \mathrm{P}_{\text {total }}=20,36 \mathrm{~g} \mathrm{~kg}^{-1}, \mathrm{~N}_{\text {Kjeldahl }}=$ $24,8 \mathrm{~g} \mathrm{~kg}^{-1}, \mathrm{pH}_{\mathrm{H} 2 \mathrm{O}}=5,80, \mathrm{~K}_{\text {total }}=2,38 \mathrm{~g} \mathrm{~kg}^{-1}, \mathrm{Na}_{\text {total }}$ $=1,08 \mathrm{~g} \mathrm{~kg}^{-1}, \mathrm{Ca}_{\text {total }}=15,87 \mathrm{~g} \mathrm{~kg}^{-1}, \mathrm{Mg}_{\text {total }}=4,23 \mathrm{~g}$ $\mathrm{kg}^{-1}$ e Umidade $=81,3 \%$.

Amostras (LE, solos, superfosfato simples, calcário, $\mathrm{KCl}$ e materiais certificados) foram digeridas segundo a metodologia 3051A da USEPA. Uma alíquota de $0,5 \mathrm{~g}$ de amostra foi digerida em $10 \mathrm{~mL}$ de ácido nítrico concentrado - $\mathrm{HNO}_{3}(65$ $\% \mathrm{v} / \mathrm{v}$ ) em grau analítico. Materiais de referência certificados RTC CRM 029-050 - lodo de esgoto e
RTC CRM 005-050 - solo contaminado com lodo de esgoto foram utilizados para avaliar a precisão e exatidão dos procedimentos de digestão e leitura dos analitos estudados. Em todas as diluições e no preparo de soluções, foi utilizada água ultrapura (resistividade 18,2 $\mathrm{M} \Omega \mathrm{cm}$ ).

$\mathrm{Na}$ construção das curvas analíticas para a determinação dos analitos, foram usadas soluçõesestoque contendo $1000 \mathrm{mg} \mathrm{L}^{-1}$ (Merck, Darmstadt, Germany) de As, $\mathrm{Ba}, \mathrm{Cd}, \mathrm{Cr}, \mathrm{Cu}, \mathrm{Hg}, \mathrm{Mo}, \mathrm{Ni}, \mathrm{Pb}$, $\mathrm{Se}$ e Zn. O elemento $\mathrm{Hg}$ foi analisado por sistema de geração química de vapor e quantificado por CVGICP-OES (SANTOS et al., 2005) e os demais foram quantificados por ICP-OES em visão axial. As condições de operação dos equipamentos ICP-OES encontram-se descritas na Tabela 3. Os teores de $\mathrm{Na}$ e $\mathrm{K}$ foram quantificados por espectrofotometria de emissão atômica por chama. A quantificação de $\mathrm{P}$ foi feita por espectrofotometria UV-Vis. 
A caracterização química do LE (base seca), conforme anexos II e IV da resolução 375 (CONAMA, 2006) foram: As $=6,71 \mathrm{mg} \mathrm{kg}^{-1}, \mathrm{Ba}=$ $2.238,89 \mathrm{mg} \mathrm{kg}^{-1}, \mathrm{Cd}=5,10 \mathrm{mg} \mathrm{kg}^{-1}, \mathrm{Cr}=671,08$ $\mathrm{mg} \mathrm{kg}{ }^{-1}, \mathrm{Cu}=629,34 \mathrm{mg} \mathrm{kg}{ }^{-1}, \mathrm{Hg}=4,37 \mathrm{mg} \mathrm{kg}$
1, $\mathrm{Mo}=4,28 \mathrm{mg} \mathrm{kg}^{-1} \mathrm{Ni}=220,85 \mathrm{mg} \mathrm{kg}^{-1}, \mathrm{~Pb}=$ $63,13 \mathrm{mg} \mathrm{kg}^{-1}$ e $\mathrm{Zn}=1.330,55 \mathrm{mg} \mathrm{kg}^{-1}$. Conforme os teores máximos permitidos pela Resolução 375 (CONAMA, 2006), apenas o teor de Ba estava em desconformidade em relação à aplicação em solos.

Tabela 3. Parâmetros operacionais do ICP-OES Varian Vista Pró e ICP-OES Thermo Scientific com configuração axial usados para análise dos elementos-traço $\mathrm{As}, \mathrm{Ba}, \mathrm{Cd}, \mathrm{Cr}, \mathrm{Cu}, \mathrm{Hg}, \mathrm{Mo}, \mathrm{Ni}, \mathrm{Pb}$, $\mathrm{Se}$ e $\mathrm{Zn}$, na análise das amostras de solos, sedimento, lodo e materiais certificados.

\begin{tabular}{|c|c|c|}
\hline $\begin{array}{l}\text { Parâmetros Operacionais/ } \\
\text { Equipamentos }\end{array}$ & Varian Vista Pró - LAQA 110 & Thermo Scientific iCAP 6500 \\
\hline Gerador de Radiofrequência & $40 \mathrm{MHz}$ & $27,12 \mathrm{MHz}$ \\
\hline Vazão do gás plasma & $15,0 \mathrm{~L} \mathrm{~min}^{-1}$ & $12 \mathrm{~L} \mathrm{~min}^{-1}$ \\
\hline Vazão do gás auxiliar & $1,5 \mathrm{~L} \mathrm{~min}^{-1}$ & $0,5 \mathrm{~L} \mathrm{~min}^{-1}$ \\
\hline Potência da fonte de Radiofrequência & $1,10 \mathrm{~kW} / 1,2 \mathrm{~kW}(\mathrm{Hg})$ & $1,15 \mathrm{~kW}$ \\
\hline Tempo de integração & $3 \mathrm{~s}$ & $15 \mathrm{~s}$ \\
\hline Tempo de estabilização & $15 \mathrm{~s} / 35 \mathrm{~s}(\mathrm{Hg})$ & \\
\hline Número de integrações & $3 / 4(\mathrm{Hg})$ & 3 \\
\hline Velocidade da bomba & $50 \mathrm{rpm}$ & $50 \mathrm{rpm}$ \\
\hline Pressão do nebulizador & $18 \mathrm{kPa} / 200 \mathrm{kPa}(\mathrm{Hg})$ & $26 \mathrm{MPa}$ \\
\hline Tipo de nebulizador & Concêntrico de vidro & Concêntrico-padrão \\
\hline Tocha & Padrão axial Varian & Duo (modo axial e radial) \\
\hline Tubo de alumina & 1,8 mm (diâmetro interno) & $2,0 \mathrm{~mm}$ \\
\hline \multicolumn{3}{|l|}{ Gerador químico de vapor } \\
\hline Acidez da amostra & $0,14 \mathrm{~mol} \mathrm{~L}^{-1} \mathrm{HNO}_{3}$ & \\
\hline Vazão da amostra & $8 \mathrm{~mL} \mathrm{~min}^{-1}$ & \\
\hline Vazão do $\mathrm{NaBH}_{4}$ e $\mathrm{HCl}$ & $1 \mathrm{~mL} \mathrm{~min}^{-1}$ & \\
\hline Vazão do gás argônio & $60 \mathrm{psi}\left(120 \mathrm{~mL} \mathrm{~min}^{-1}\right)$ & \\
\hline \multirow[t]{8}{*}{ Linhas analíticas } & As $188,890 \mathrm{~nm}$ & $\mathrm{Ba} 493,409 \mathrm{~nm}$ \\
\hline & $\operatorname{Hg} 253,652 \mathrm{~nm}$ & $\mathrm{Cd} 214,439 \mathrm{~nm}$ \\
\hline & Se $196,026 \mathrm{~nm}$ & $\mathrm{Cr} 283,563 \mathrm{~nm}$ \\
\hline & & $\mathrm{Cu} 324,754 \mathrm{~nm}$ \\
\hline & & Mo $202,030 \mathrm{~nm}$ \\
\hline & & Ni $231,604 \mathrm{~nm}$ \\
\hline & & $\mathrm{Pb} 220,353 \mathrm{~nm}$ \\
\hline & & Zn $213,856 \mathrm{~nm}$ \\
\hline
\end{tabular}

Fonte: Elaboração dos autores.

Foi constatada a necessidade de se elevar a saturação por bases dos solos para 70\% em todas as parcelas dos tratamentos. Assim foram aplicadas doses de calcário agrícola $(\mathrm{PRNT}=90 \%)$ que variaram de 2,52 a 4,0 t ha $\mathrm{h}^{-1}$ no LVef e de 1,23 a 2,71 t ha ${ }^{-1}$ no LVd. A incorporação do LE ao solo conforme os tratamentos estabelecidos, deu-se em dezembro de 2009; foi levado em conta a umidade residual $(81,3 \%)$ do mesmo. O LE foi aplicado a lanço e incorporado por meio de leve gradagem. Conforme os atributos químicos de NPK dos solos (Tabela 2) e LE $\left(\mathrm{N}_{\text {Kjeldahl }}=24,8 \mathrm{~g} \mathrm{~kg}^{-1}, \mathrm{P}_{\text {total }}=20,36\right.$ $\left.\mathrm{g} \mathrm{kg}^{-1}, \mathrm{~K}_{\text {total }}=2,38 \mathrm{~g} \mathrm{~kg}^{-1}\right)$, a diferença entre $\mathrm{o}$ teor de NPK exigido pela cultura do milho (RAIJ; CANTARELLA, 1997) e o disponibilizado pelo LE foi complementado por meio de fertilizantes 
minerais convencionais. Durante o período de experimentação, a precipitação pluviométrica total foi de $821 \mathrm{~mm}$.

Com o programa AgroEstat - Sistema para Análises Estatísticas de Ensaios Agronômicos (BARBOSA; MALDONADO JÚNIOR, 2010), os dados foram submetidos à análise de variância; e quando o teste $\mathrm{F}$ foi significativo, houve comparação das médias utilizando o teste de Tukey em nível de significância $(\alpha=0,05)$. Em função de alguns ajustes na configuração do experimento nesses treze anos (ex. alteração da dose T 2,5 tha ${ }^{-1}$ de LE, base seca, para $\mathrm{T} 20 \mathrm{t} \mathrm{ha}^{-1}$ de LE, base seca, etc), não foi possível realizar análise de regressão.

\section{Resultados e Discussão}

Exceto Mo (43,4 e 45,1\%), os índices de recuperação dos elementos-traço (ETs) nos materiais de referência certificados variaram entre 73,5 a 127,4\% (Tabela 4). Conforme o escopo e aplicação do método 3051A do USEPA, esta metodologia não realiza uma decomposição total de sedimentos, solos e lodos, de tal forma que este procedimento é mais indicado para estudos de contaminação e poluição ambiental, pois representa o máximo potencialmente biodisponível de um dado poluente.

Tabela 4. Teores dos elementos traço (As, $\mathrm{Ba}, \mathrm{Cd}, \mathrm{Cr}, \mathrm{Cu}, \mathrm{Hg}$, Mo, Ni, Pb, Se e Zn) obtidos dos materiais de referência certificados solo contaminado com lodo de esgoto - RTC CRM 005-050 e lodo de esgoto - RTC CRM 029-050.

\begin{tabular}{|c|c|c|c|c|}
\hline Elemento-traço & Material Certificado & Teor Certificado & Teor determinado $(n=3)$ & Recuperação \\
\hline & & \multicolumn{2}{|c|}{ 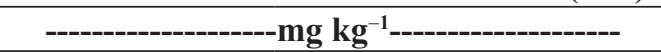 } & $\%$ \\
\hline \multirow[t]{2}{*}{ As } & RTC CRM 005-050 & 6,91 & 7,50 & 108,5 \\
\hline & RTC CRM 029-050 & $27,4 \pm 2,75$ & 23,91 & 87,3 \\
\hline \multirow[t]{2}{*}{ Ba } & RTC CRM 005-050 & 852,9 & $1.086,52$ & 127,4 \\
\hline & RTC CRM 029-050 & $1080 \pm 61,8$ & 993,30 & 92,0 \\
\hline \multirow[t]{2}{*}{ Cd } & RTC CRM 005-050 & 13,7 & 13,76 & 100,4 \\
\hline & RTC CRM 029-050 & $487 \pm 17,5$ & 502,13 & 103,1 \\
\hline \multirow[t]{2}{*}{$\mathrm{Cr}$} & RTC CRM 005-050 & 41,3 & 48,06 & 117,2 \\
\hline & RTC CRM 029-050 & $345 \pm 15,1$ & 372,20 & 107,9 \\
\hline \multirow[t]{2}{*}{$\mathbf{C u}$} & RTC CRM 005-050 & 465,4 & 387,76 & 83,3 \\
\hline & RTC CRM 029-050 & $1100 \pm 24,0$ & $1.024,57$ & 93,14 \\
\hline \multirow[t]{2}{*}{ Hg } & RTC CRM 005-050 & 3,23 & 3,25 & 100,6 \\
\hline & RTC CRM 029-050 & $6,13 \pm 0,699$ & 6,62 & 108,0 \\
\hline \multirow[t]{2}{*}{ Mo } & RTC CRM 005-050 & 14,2 & 6,41 & 45,1 \\
\hline & RTC CRM 029-050 & $19,1 \pm 0,934$ & 8,29 & 43,4 \\
\hline \multirow[t]{2}{*}{$\mathbf{N i}$} & RTC CRM 005-050 & 26,0 & 29,95 & 115,2 \\
\hline & RTC CRM 029-050 & $172 \pm 8,31$ & 186,24 & 108,3 \\
\hline \multirow[t]{2}{*}{$\mathbf{P b}$} & RTC CRM 005-050 & 89,2 & 110,82 & 124,2 \\
\hline & RTC CRM 029-050 & $300 \pm 11,8$ & 325,99 & 108,7 \\
\hline \multirow[t]{2}{*}{ Se } & RTC CRM 005-050 & 19,9 & 16,61 & 83,5 \\
\hline & RTC CRM 029-050 & $25,4 \pm 3,27$ & 18,65 & 73,4 \\
\hline \multirow[t]{2}{*}{ Zn } & RTC CRM 005-050 & 625,2 & 619,25 & 99,05 \\
\hline & RTC CRM 029-050 & $1400 \pm 33,8$ & 1334,12 & 95,29 \\
\hline
\end{tabular}

Fonte: Elaboração dos autores. 
Portanto, a escolha do método de digestão 3051A da USEPA, utilizando apenas ácido nítrico concentrado $(65 \% \mathrm{v} / \mathrm{v})-\mathrm{HNO}_{3}$ teve como objetivo reproduzir a disponibilidade ambiental dos ETs em laboratório. Assim, as taxas de recuperação foram robustas para avaliar a precisão e exatidão dos métodos de digestão e leitura dos analitos, quando comparado com outras digestões ácidas (águarégia $+\mathrm{H}_{2} \mathrm{O}_{2}+\mathrm{HF}$ ) muito mais enérgicas como as realizadas por Chen e Ma (2001) e Vieira et al. (2005).

Conforme a Instrução Normativa 27 da Secretaria de Defesa Agropecuária - SDA do Ministério da Agricultura, Pecuária e Abastecimento (MAPA, 2006), nos seus anexos I, II e III, as análises do superfosfato simples, calcário e $\mathrm{KCl}$ aplicados na condução do experimento demonstraram que o uso de doses agronômicas, não representa risco potencial no aumento da concentração dos ETs acima dos teores naturalmente encontrados em solos, corroborando outros trabalhos (MENDES et al., 2006; BIZARRO; MEURER; TATSCH, 2008) (Tabela 5). McBride e Spiers (2001) relataram que um aumento significativo do teor de ETs nos solos pela aplicação de fertilizantes pode levar décadas, embora deva ser enfatizado que não somente a concentração do ETs no insumo, mas também a dose de insumo aplicada e o número de aplicações devem ser levados em consideração. A contaminação antrópica do solo por ETs provocada pela aplicação de fertilizantes parece irrelevante, porém requer monitoramento, pois seu uso é mais amplamente disseminado que outros agroquímicos (RAVEN; LOEPPERT, 1997).

Entre as várias alternativas de disposição final do LE, recomenda-se a utilização como condicionador de solos degradados devido à riqueza em matéria orgânica (70\%) dos sólidos constituintes (MELO; MARQUES, 2000). Assim, conforme o anexo IV da Instrução Normativa 27 da SDA (MAPA, 2006), o LE utilizado apresentou teor de $\mathrm{Cr}$ acima do valor regulamentado como condicionador de solos, porém, ainda dentro do limite de $30 \%$ tolerado pelo artigo $3^{\circ}$ da norma (Tabela 5). O teor de $\mathrm{Hg}(4,37$ $\mathrm{mg} \mathrm{kg}^{-1}$ ) apresentou-se acima do limite estabelecido (2,5 $\left.\mathrm{mg} \mathrm{kg}^{-1}\right)$, portanto, o LE não pode ser utilizado em área agrícola.

Poucos trabalhos publicados realizaram comparação entre métodos de digestão e extração de ET em fertilizantes e corretivos agrícolas; Bizarro, Meurer e Tatsch (2008) compararam os métodos USEPA 3050B e nitro-perclórico para fertilizantes fosfatados e constataram que o último apresentou melhor extração de $\mathrm{Cd}$.

Campos et al. (2005) avaliaram os teores de Cd, $\mathrm{Cu}, \mathrm{Cr}, \mathrm{Ni}, \mathrm{Pb}$ e $\mathrm{Zn}$ em fertilizantes fosfatados através dos métodos USEPA 3050B e 3051A e constataram que a extração em micro-ondas (3051A) não só é menos poluidora como também resulta em menor perda de elementos por volatilização e secagem da solução extratora. Além disso, proporciona menor tempo de digestão, boa recuperação de muitos dos elementos voláteis, reduz o risco de contaminação externa e requer menor quantidade de ácidos (BETTINELLI et al., 2000).

Quanto aos teores de $\mathrm{Cr}, \mathrm{Cu}, \mathrm{Ni}, \mathrm{Pb}$ e $\mathrm{Zn}$ no LVef e $\mathrm{Ba}, \mathrm{Cu}, \mathrm{Ni}, \mathrm{Pb}$ e $\mathrm{Zn}$ no LVd, observou-se que houve efeito significativo das doses de LE nas concentrações desses elementos químicos nos solos (Tabela 6). Esses resultados são concordantes, corroborando com outros trabalhos realizados nas mesmas áreas para alguns ETs (OLIVEIRA et al., 2005; NOGUEIRA et al., 2008; MERLINO et al., 2010).

$\mathrm{Na}$ análise conjunta dos experimentos constatouse que só houve diferença significativa em relação aos tratamentos para os elementos $\mathrm{Pb}$ e $\mathrm{Zn}$; na análise em relação aos experimentos, demonstra elevada significância ao nível de $1 \%$ para a maioria dos ETs (Tabelas 6 e 7). Embora os elementos Mo e Se tenham sido incorporados aos solos nos tratamentos com LE, os teores estavam abaixo do limite de detecção do método analítico. 
Tabela 5. Teores médios dos elementos traço ( $\mathrm{As}, \mathrm{Ba}, \mathrm{Cd}, \mathrm{Pb}, \mathrm{Cu}, \mathrm{Cr}, \mathrm{Hg}, \mathrm{Mo}, \mathrm{Ni}$, $\mathrm{Se}$ e $\mathrm{Zn}$ ) encontrados nos insumos (lodo de esgoto, calcário, superfosfato simples, cloreto de potássio) aplicados no ciclo agrícola 2009/2010 e valores máximos permitidos pela Resolução 375 (CONAMA, 2006) e Instrução Normativa 27 (MAPA, 2006). (n=3).

\begin{tabular}{|c|c|c|c|c|c|c|c|c|c|c|c|}
\hline \multirow[b]{3}{*}{ Insumos e VM${ }^{(1)}$} & \multicolumn{11}{|c|}{ Elementos traço } \\
\hline & As & Ba & Cd & $\mathrm{Cr}$ & $\mathrm{Cu}$ & $\mathrm{Hg}$ & Mo & $\mathbf{N i}$ & $\mathbf{P b}$ & Se & $\mathrm{Zn}$ \\
\hline & \multicolumn{11}{|c|}{$\begin{array}{l} \\
\end{array}$} \\
\hline Lodo de esgoto & 6,71 & 2238,89 & 5,10 & 671,08 & 629,34 & 4,37 & 4,28 & 277,54 & 63,13 & $<0,05$ & 1330,55 \\
\hline Calcário & 3,34 & 44,02 & 2,34 & 11,75 & 3,19 & 0,06 & 0,36 & 1,19 & $<0,001$ & $<0,05$ & 8,02 \\
\hline Superfosfato simples ${ }^{(2)}$ & 35,18 & 428,96 & 2,82 & 24,71 & 17,57 & 0,03 & 1,64 & 16,94 & 13,58 & $<0,05$ & 81,28 \\
\hline $\begin{array}{l}\text { Cloreto de potássio - } \\
\text { KCl }\end{array}$ & 0,99 & 995,24 & 0,81 & 1,12 & 1,83 & 0,03 & $<0,001$ & $<0,005$ & 0,39 & $<0,05$ & 24,14 \\
\hline $\begin{array}{l}\text { Resolução } 375 \\
\text { (CONAMA, 2006) }\end{array}$ & 41 & 1300 & 39 & 1000 & 1500 & 17 & 50 & 420 & 300 & 100 & 2800 \\
\hline $\begin{array}{l}\text { Instr. Normat. } \\
27 \text { (MAPA, 2006) } \\
\text { Fertilizantes } \\
\text { Orgânicos }\end{array}$ & 20 & - & 3 & 200 & - & 1 & - & 70 & 150 & 80 & - \\
\hline $\begin{array}{l}\text { Instr. Normat. } \\
27 \text { (MAPA, 2006) } \\
\text { Condicionadores de } \\
\text { solo }\end{array}$ & 20 & - & 8 & 500 & - & 2,5 & - & 175 & 300 & 80 & - \\
\hline $\begin{array}{l}\text { Instr. Normat. } \\
27 \text { (MAPA, 2006) } \\
\text { Corretivos de solo }\end{array}$ & - & - & 20 & - & - & - & - & - & 1000 & - & - \\
\hline $\begin{array}{l}\text { Instr. Normat. } \\
27 \text { (MAPA, 2006) } \\
\text { Fertilizantes minerais } \\
\text { com } \mathrm{P}_{2} \mathrm{O}_{5}^{(2)}\end{array}$ & 36 & - & 72 & 720 & - & 0,90 & - & - & - & 360 & - \\
\hline $\begin{array}{l}\text { Instr. Normat. } \\
27 \text { (MAPA, 2006) } \\
\text { Fertilizantes minerais } \\
\text { com KCl }\end{array}$ & 10 & - & 20 & 200 & - & 0,20 & - & - & 100 & - & - \\
\hline
\end{tabular}

${ }^{(1)}$ Valor Máximo, ${ }^{(2)}$ fertilizante mineral com $18 \%$ de $\mathrm{P}_{2} \mathrm{O}_{5}$.

Fonte: Elaboração dos autores.

Exceto para $\mathrm{Hg}$ (Tabelas 6 e 7), os maiores teores dos ETs foram encontrados no LVef, o qual é de textura argilosa, comparado com o LVd que é de textura média. Isso comprova que, com maior teor de matéria orgânica (21,4 a 26,2 $\left.\mathrm{g} \mathrm{dm}^{-3}\right)$, maior CTC $\left(83,86\right.$ a $\left.101,58 \mathrm{mmol}_{\mathrm{c}} \mathrm{dm}^{-3}\right)$ e horizonte A moderado caulinítico-oxídico, o LVef proporcionou maior retenção dos ETs quando comparado ao LVd o qual apresentou menor teor de matéria orgânica $(19,4$ a 21,2 $\left.\mathrm{g} \mathrm{dm}^{-3}\right)$, menor CTC (64,54 a 75,60 $\mathrm{mmol}_{\mathrm{c}} \mathrm{dm}^{-}$ ${ }^{3}$ ) e possui horizonte A moderado caulinítico.

Em geral, a movimentação dos ETs no perfil do solo esta condicionada às suas naturezas químicas e aos atributos do solo, os quais interferem nas reações de sorção/dessorção, precipitação/ dissolução, complexação, formação de quelatos e oxirredução (OLIVEIRA; MATTIAZZO, 2001). Dentre os atributos do solo que podem interferir na mobilidade dos ETs, pode-se destacar o $\mathrm{pH}$, teor de matéria orgânica, potencial redox, tipo e quantidade da argila, textura e ação dos exsudatos liberados pelas raízes, que facilita a biodisponibilidade (RIEUWERTS et al., 2006). Os óxidos de Fe da fração argila e o ácido fúlvico da matéria orgânica são mais efetivos na adsorção dos elementos traço (COVELO; VEGA; ANDRADE, 2007). 
Pesquisas têm demonstrado que $\mathrm{Cr}, \mathrm{Cu}, \mathrm{Ni}$ e $\mathrm{Pb}$ apresentam baixa mobilidade, acumulandose na camada superficial do solo onde o LE foi incorporado, enquanto que o $\mathrm{Cd}$ e $\mathrm{Zn}$, principalmente o Zn, são móveis e, portanto, apresentam maior potencial para percolar e contaminar o subsolo e as águas subterrâneas (OLIVEIRA; MATTIAZZO, 2001; OLIVEIRA et al., 2005; NOGUEIRA et al., 2008; MERLINO et al., 2010).

Após a $13^{\mathrm{a}}$ aplicação de LE ao LVef e LVd, análises químicas dos teores dos ETs (As, Ba, Cd, $\mathrm{Cr}, \mathrm{Cu}, \mathrm{Hg}, \mathrm{Mo}, \mathrm{Ni}, \mathrm{Pb}$, Se e Zn) obtidos e de acordo com os teores máximos permitidos pela Decisão de diretoria $\mathrm{n}^{\circ} 195$ (CETESB, 2005), que trata dos valores orientadores para solos e águas subterrâneas no Estado de São Paulo (valores de referência de qualidade - VRQ) e pela resolução 420 (CONAMA, 2009) (valores de prevenção - VP), constatou-se que o LVef apresentou teores de $\mathrm{As}, \mathrm{Ba}, \mathrm{Cd}, \mathrm{Cr}, \mathrm{Cu}$, $\mathrm{Hg}$, Ni e Zn acima dos VRQ e teores de Cd, Cr e $\mathrm{Cu}$ acima dos VP; o LVd apresentou teores de As, $\mathrm{Cd}, \mathrm{Cr}, \mathrm{Hg}$ e $\mathrm{Zn}$ (dois tratamentos) acima dos VRQ e teor Cr acima dos VP. O LVef e o LVd apresentam teores de ETs abaixo dos valores de investigação (VI) agrícola, o qual é o mais restritivo (Tabela 7).

Portanto, os dois Latossolos, conforme o art. 13 da resolução 420 (CONAMA, 2009) que trata das classes de qualidade dos solos, são de Classe 3, visto que, o solo apresentou pelo menos uma substância química com teor maior que o VP e menor ou igual ao VI (valor de investigação).

Comparando os teores dos elementos As, Ba, $\mathrm{Cu}, \mathrm{Hg}, \mathrm{Ni}, \mathrm{Pb}$ e $\mathrm{Zn}$ nos tratamentos que receberam LE no $12^{\circ}$ ano e $13^{\circ}$ ano, constatou-se diminuição nos teores de alguns tratamentos (Tabelas 6 e 7). Também ocorreu diminuição nos teores de $\mathrm{Cd}$ e $\mathrm{Cr}$ em todos os tratamentos que receberam LE. Essa diminuição se deve provavelmente ao elevado índice pluviométrico $(821 \mathrm{~mm})$ ocorrido durante a condução do experimento e a possibilidade desses elementos terem sido lixiviados para camadas abaixo de 0,2 m. Pode-se notar mais claramente no LVd, pois trata-se de um Latossolo de textura média.

Nos ecossistemas tropicais, onde predominam solos altamente intemperizados, a movimentação dos ETs no perfil do solo é governada principalmente pelo regime hídrico, $\mathrm{pH}$ do solo, capacidade de retenção do solo através da formação de complexo de esfera interna com os óxidos de $\mathrm{Fe}$ e $\mathrm{Al}$ e com a matéria orgânica e posição do solo na paisagem (KASHEM; SINGH; KAWAI, 2007; SALVADORBLANES et al., 2006).

Nos cinco primeiros anos, Oliveira et al. (2005) relataram que o LE aplicado nos dois Latossolos estudados apresentava teores médios de $644,2 \mathrm{mg} \mathrm{kg}$, $385,4 \mathrm{mg} \mathrm{kg} \mathrm{kg}^{-1}$ e $2.407,4 \mathrm{mg}$ $\mathrm{kg}^{-1}$, respectivamente, para $\mathrm{Cu}, \mathrm{Ni}$ e $\mathrm{Zn}$. E assim, permaneceu com elevada carga impactante até o $13^{\circ}$ ano $\left(\mathrm{Cu}=629,3 \mathrm{mg} \mathrm{kg}^{-1}, \mathrm{Ni}=220,8 \mathrm{mg} \mathrm{kg}^{-1}\right.$ e $\mathrm{Zn}$ $\left.=1.330,5 \mathrm{mg} \mathrm{kg}^{-1}\right)$. Portanto, os teores de $\mathrm{Cu}$, Ni e $\mathrm{Zn}$ nos solos (LVd e LVef) sofreram elevações de até $246 \%$ e $199 \%$ para Cu, $161 \%$ e $201 \%$ para Ni e $297 \%$ e $161 \%$ para $\mathrm{Zn}$, respectivamente. Oliveira et al. (2005) relataram teor médio de 205,8 $\mathrm{mg} \mathrm{kg}^{-1}$ do elemento $\mathrm{Pb}$ no LE aplicado aos solos, porém a carga impactante média foi decrescendo até o $13^{\circ}$ ano $\left(63,14 \mathrm{mg} \mathrm{kg}^{-1}\right)$. Dessa maneira, os teores de $\mathrm{Pb}$ nos solos (LVd e LVef) sofreram diminuição de até $48 \%$ e $62 \%$ respectivamente.

Portanto, fica evidente que, aplicações anuais sucessivas de LE com elevadas concentrações de ETs certamente levarão a um acúmulo desses elementos químicos na camada superficial do solo. Assim, considerando os teores orientadores dos ETs para solos preconizados pela resolução 420 (CONAMA, 2009) e tendo como base os teores médios dos ETs incrementados no solo através do LE utilizado, acredita-se que o $\mathrm{Ba}, \mathrm{Cd}, \mathrm{Cr}, \mathrm{Cu}$, Ni e Zn serão os primeiros elementos químicos a atingirem o VI no LVef (Tabela 8). 
Tabela 6. Teores médios dos elementos-traço (As, $\mathrm{Ba}, \mathrm{Cd}, \mathrm{Cr}, \mathrm{Cu}, \mathrm{Hg}, \mathrm{Mo}, \mathrm{Ni}, \mathrm{Pb}, \mathrm{Se}$ e $\mathrm{Zn}$ ) em Latossolo Vermelho eutroférrico (LVef) e Latossolo Vermelho distrófico (LVd) na profundidade de 0,0-0,20 m, que receberam LE por 12 anos, antes da semeadura, no ciclo agrícola de 2009/2010.

\begin{tabular}{|c|c|c|c|c|c|c|c|c|c|c|c|}
\hline $\begin{array}{l}\text { Lodo de } \\
\text { esgoto }\end{array}$ & As & $\mathrm{Ba}$ & Cd & $\mathrm{Cr}$ & $\mathrm{Cu}$ & $\mathbf{H g}$ & Mo & $\mathrm{Ni}$ & $\mathbf{P b}$ & Se & Zn \\
\hline $\begin{array}{l}\text { t ha }^{-1} \mathrm{e} \\
\text { Referências }\end{array}$ & \multicolumn{11}{|c|}{$\mathrm{mg} \mathrm{kg}^{-1}$ de solo } \\
\hline \multicolumn{12}{|c|}{ - } \\
\hline T 0 & $5,49 \mathrm{a}$ & $121,30 \mathrm{a}$ & $1,55 \mathrm{a}$ & $151,45 a b$ & $129,66 a b$ & $0,08 \mathrm{a}$ & $<0,001$ & $24,72 \mathrm{ab}$ & $5,83 \mathrm{c}$ & $<0,05$ & $105,91 \mathrm{~b}$ \\
\hline T 5 & $6,06 \mathrm{a}$ & $111,97 \mathrm{a}$ & $1,71 \mathrm{a}$ & $144,88 \mathrm{~b}$ & $120,16 \mathrm{~b}$ & $0,10 \mathrm{a}$ & $<0,001$ & $21,64 \mathrm{~b}$ & $6,26 \mathrm{bc}$ & $<0,05$ & $104,38 \mathrm{~b}$ \\
\hline T 10 & $5,52 \mathrm{a}$ & $122,11 \mathrm{a}$ & $1,98 \mathrm{a}$ & $156,74 \mathrm{ab}$ & $135,19 \mathrm{ab}$ & $0,14 \mathrm{a}$ & $<0,001$ & $26,75 \mathrm{ab}$ & $7,94 \mathrm{ab}$ & $<0,05$ & $132,39 \mathrm{ab}$ \\
\hline T 20 & $6,48 \mathrm{a}$ & $139,69 \mathrm{a}$ & $1,72 \mathrm{a}$ & $162,27 \mathrm{a}$ & $147,20 \mathrm{a}$ & $0,14 \mathrm{a}$ & $<0,001$ & $31,22 \mathrm{a}$ & $9,13 \mathrm{a}$ & $<0,05$ & $149,84 \mathrm{a}$ \\
\hline Média & 5,89 & 123,77 & 1,74 & 153,84 & 133,05 & 0,11 & - & 26,08 & 7,29 & - & 123,13 \\
\hline Teste F & $1,33^{\mathrm{NS}}$ & $2,12^{\mathrm{NS}}$ & $2,40^{\mathrm{NS}}$ & $5,79 *$ & $3,53^{*}$ & $3,75^{*}$ & - & 3,23 NS & $9,37 * *$ & - & $7,03 * *$ \\
\hline DMS & 1,73 & 33,33 & 0,48 & 12,96 & 25,22 & 0,07 & - & 9,39 & 2,09 & - & 34,79 \\
\hline $\mathrm{CV} \%$ & 15,6 & 14,3 & 14,8 & 4,5 & 10,1 & 31,6 & - & 19,2 & 15,3 & - & 15,0 \\
\hline \multicolumn{12}{|c|}{---10 } \\
\hline T 0 & $3,58 \mathrm{a}$ & $19,40 \mathrm{~b}$ & $0,98 \mathrm{a}$ & 82,89 a & $10,93 \mathrm{~b}$ & $0,13 \mathrm{a}$ & $<0,001$ & $5,74 \mathrm{~b}$ & $4,54 \mathrm{~b}$ & $<0,05$ & $26,34 \mathrm{c}$ \\
\hline T 5 & 3,16 a & $22,13 \mathrm{~b}$ & $1,10 \mathrm{a}$ & 87,59 a & $16,10 \mathrm{~b}$ & $0,25 \mathrm{a}$ & $<0,001$ & $7,09 \mathrm{~b}$ & $5,65 \mathrm{~b}$ & $<0,05$ & $43,60 \mathrm{~b}$ \\
\hline T 10 & $3,52 \mathrm{a}$ & $30,69 \mathrm{a}$ & $1,22 \mathrm{a}$ & $105,93 \mathrm{a}$ & $27,27 \mathrm{a}$ & $0,29 \mathrm{a}$ & $<0,001$ & $11,14 \mathrm{a}$ & $7,27 \mathrm{a}$ & $<0,05$ & $72,35 \mathrm{a}$ \\
\hline T 20 & $4,14 \mathrm{a}$ & $31,16 \mathrm{a}$ & $1,17 \mathrm{a}$ & 128,16 a & $31,80 \mathrm{a}$ & $0,22 \mathrm{a}$ & $<0,001$ & $11,02 \mathrm{a}$ & $8,15 \mathrm{a}$ & $<0,05$ & $70,12 \mathrm{a}$ \\
\hline Média & 3,60 & 25,84 & 1,12 & 101,14 & 21,52 & 0,22 & - & 8,75 & 6,40 & - & 53,10 \\
\hline Teste F & $2,98^{\mathrm{NS}}$ & $32,77 * *$ & $0,80^{\mathrm{NS}}$ & $2,25^{\mathrm{NS}}$ & $45,03 * *$ & $2,85^{\mathrm{NS}}$ & - & $29,63^{* *}$ & $19,61^{* *}$ & - & $33,38 * *$ \\
\hline DMS & 0,99 & 4,38 & 0,48 & 57,64 & 6,05 & 0,17 & - & 2,12 & 1,53 & - & 16,07 \\
\hline $\mathrm{CV} \%$ & 14,6 & 9,0 & 23,1 & 30,3 & 15,0 & 40,1 & - & 12,9 & 12,7 & - & 16,1 \\
\hline $\begin{array}{l}\text { Referência } \\
\text { CETESB } \\
\text { (2005) }\end{array}$ & 3,5 & 75 & $<0,5$ & 40 & 35 & 0,05 & $<4$ & 13 & 17 & 0,25 & 60 \\
\hline $\begin{array}{l}\text { Teor de } \\
\text { Prevenção } \\
\text { Resol. } \\
420 / 2009 \\
\text { CONAMA }\end{array}$ & 15 & 150 & 1,3 & 75 & 60 & 0,5 & 30 & 30 & 72 & 5 & 300 \\
\hline $\begin{array}{l}\text { Teor de } \\
\text { Investig./ } \\
\text { Agrícola } \\
\text { Resol. } \\
420 / 2009 \\
\text { CONAMA }\end{array}$ & 35 & 300 & 3 & 150 & 200 & 12 & 50 & 70 & 180 & - & 450 \\
\hline \multicolumn{12}{|c|}{ Análise conjunta dos experimentos } \\
\hline Teste F p/ T & $2,90^{\mathrm{NS}}$ & $3,31^{\mathrm{NS}}$ & $7,66^{\mathrm{NS}}$ & $3,62^{\mathrm{NS}}$ & $8,77^{\mathrm{NS}}$ & $3,29^{\mathrm{NS}}$ & - & $5,57^{\mathrm{NS}}$ & $99,84 * *$ & - & $14,73^{*}$ \\
\hline Teste F p/ E & $104,32 * *$ & $487,32 * *$ & $158,06^{* *}$ & $53,59 * *$ & $1100,13 * *$ & $18,73^{*}$ & - & $166,39 * *$ & $32,33^{*}$ & - & $158,87 * *$ \\
\hline $\begin{array}{l}\text { Teste F p/ T } \\
\mathbf{x} \mathbf{E}\end{array}$ & $0,89^{\mathrm{NS}}$ & $1,23^{\mathrm{NS}}$ & $1,90^{\mathrm{NS}}$ & $1,05^{\mathrm{NS}}$ & $1,18^{\mathrm{NS}}$ & $1,39^{\mathrm{NS}}$ & - & $1,37^{\mathrm{NS}}$ & $0,26^{\mathrm{NS}}$ & - & $1,48^{\mathrm{NS}}$ \\
\hline
\end{tabular}

$\mathrm{CV}=$ coeficiente de variação; $\mathrm{DMS}=$ diferença mínima significativa; $\mathrm{E}=$ experimentos; $\mathrm{T}=$ tratamentos; ${ }^{(*)}$ Médias seguidas de mesma letra, em coluna, não diferem entre si ao nível de $5 \%$ de probabilidade, pelo teste de Tukey, $*, * * \mathrm{e}^{\mathrm{NS}}-$ significativo ao nível de $5 \%(\mathrm{P}<0,05), 1 \%(\mathrm{P}<0,01)$ e não significativo $(\mathrm{P}>0,05)$, respectivamente.

Fonte: Elaboração dos autores. 
Tabela 7. Teores médios dos elementos-traço (As, $\mathrm{Ba}, \mathrm{Cd}, \mathrm{Cr}, \mathrm{Cu}, \mathrm{Hg}, \mathrm{Mo}, \mathrm{Ni}, \mathrm{Pb}$, Se e $\mathrm{Zn}$ ) em Latossolo Vermelho eutroférrico (LVef) e Latossolo Vermelho distrófico (LVd), na profundidade 0,0-0,20 m, 70 dias após receber LE ( $13^{\circ}$ ano) e semeadura de milho no ciclo agrícola de 2009/2010.

\begin{tabular}{|c|c|c|c|c|c|c|c|c|c|c|c|}
\hline $\begin{array}{l}\text { Lodo de } \\
\text { esgoto }\end{array}$ & As & Ba & Cd & $\mathrm{Cr}$ & $\mathrm{Cu}$ & $\mathbf{H g}$ & Mo & Ni & $\mathbf{P b}$ & Se & Zn \\
\hline $\begin{array}{l}\text { t ha } \mathbf{~}^{-1} \mathrm{e} \\
\text { Referências }\end{array}$ & \multicolumn{11}{|c|}{$\mathrm{mg} \mathrm{kg}^{-1}$ de solo } \\
\hline \multicolumn{12}{|c|}{ - - } \\
\hline T 0 & $5,80 \mathrm{a}$ & $110,77 \mathrm{a}$ & $1,70 \mathrm{a}$ & $135,38 \mathrm{a}$ & $121,57 \mathrm{a}$ & $0,08 \mathrm{a}$ & $<0,001$ & $22,29 \mathrm{a}$ & $5,83 \mathrm{a}$ & $<0,05$ & $97,91 \mathrm{~b}$ \\
\hline T 5 & $5,86 \mathrm{a}$ & $113,58 \mathrm{a}$ & $1,42 \mathrm{a}$ & $138,78 \mathrm{a}$ & $122,66 \mathrm{a}$ & $0,09 \mathrm{a}$ & $<0,001$ & $23,70 \mathrm{a}$ & $6,77 \mathrm{a}$ & $<0,05$ & $107,24 \mathrm{ab}$ \\
\hline T 10 & $5,66 \mathrm{a}$ & $133,69 a$ & $1,67 \mathrm{a}$ & $143,78 \mathrm{a}$ & $135,74 \mathrm{a}$ & $0,11 \mathrm{a}$ & $<0,001$ & $28,82 \mathrm{a}$ & $7,63 \mathrm{a}$ & $<0,05$ & $129,26 \mathrm{ab}$ \\
\hline T 20 & $5,69 \mathrm{a}$ & $109,57 \mathrm{a}$ & $1,60 \mathrm{a}$ & $144,14 \mathrm{a}$ & $126,66 \mathrm{a}$ & $0,11 \mathrm{a}$ & $<0,001$ & $24,52 \mathrm{a}$ & $8,00 \mathrm{a}$ & $<0,05$ & $135,46 \mathrm{a}$ \\
\hline Média & 5,75 & 116,90 & 1,60 & 140,52 & 126,66 & 0,10 & - & 24,83 & 7,06 & - & 117,47 \\
\hline Teste F & $0,02^{\mathrm{NS}}$ & $1,59^{\mathrm{NS}}$ & $1,88^{\mathrm{NS}}$ & $2,71^{\mathrm{NS}}$ & $0,97^{\mathrm{NS}}$ & $0,73^{\mathrm{NS}}$ & - & $1,47^{\mathrm{NS}}$ & $3,33^{\mathrm{NS}}$ & - & $4,84^{*}$ \\
\hline DMS & 2,54 & 37,64 & 0,38 & 10,75 & 27,41 & 0,08 & - & 9,73 & 2,22 & - & 33,98 \\
\hline CV \% & 23,5 & 17,1 & 12,8 & 4,1 & 11,5 & 43,3 & - & 20,9 & 16,7 & - & 15,4 \\
\hline \multicolumn{12}{|c|}{ 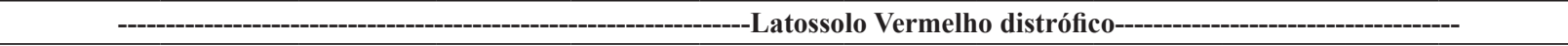 } \\
\hline T 0 & $3,06 \mathrm{a}$ & $32,55 \mathrm{a}$ & $0,48 \mathrm{a}$ & $76,01 \mathrm{c}$ & $10,27 \mathrm{c}$ & $0,15 \mathrm{a}$ & $<0,001$ & $4,88 \mathrm{c}$ & $4,32 \mathrm{~b}$ & $<0,05$ & $24,51 \mathrm{~b}$ \\
\hline T 5 & $3,56 \mathrm{a}$ & $24,30 \mathrm{a}$ & $0,56 \mathrm{a}$ & $82,77 \mathrm{bc}$ & $15,32 \mathrm{c}$ & $0,20 \mathrm{a}$ & $<0,001$ & $6,73 \mathrm{bc}$ & $5,10 \mathrm{~b}$ & $<0,05$ & $38,01 \mathrm{~b}$ \\
\hline T 10 & $3,64 \mathrm{a}$ & $29,76 \mathrm{a}$ & $0,62 \mathrm{a}$ & $95,41 \mathrm{ab}$ & $22,76 \mathrm{~b}$ & $0,24 \mathrm{a}$ & $<0,001$ & $9,27 \mathrm{ab}$ & $6,36 \mathrm{a}$ & $<0,05$ & $61,10 \mathrm{a}$ \\
\hline T 20 & $3,76 \mathrm{a}$ & $44,78 \mathrm{a}$ & $0,66 \mathrm{a}$ & $99,00 \mathrm{a}$ & $29,40 \mathrm{a}$ & $0,19 \mathrm{a}$ & $<0,001$ & $11,01 \mathrm{a}$ & $7,02 \mathrm{a}$ & $<0,05$ & $66,63 \mathrm{a}$ \\
\hline Média & 3,51 & 32,85 & 0,58 & 88,30 & 19,44 & 0,19 & - & 7,97 & 5,70 & - & 47,56 \\
\hline Teste F & $0,75^{\mathrm{NS}}$ & $2,23^{\mathrm{NS}}$ & $2,27^{\mathrm{NS}}$ & $12,53 * *$ & $30,22 * *$ & $0,54^{\mathrm{NS}}$ & - & $15,92 * *$ & $27,94 * *$ & - & $27,15^{* *}$ \\
\hline DMS & 1,50 & 24,32 & 0,22 & 12,75 & 6,41 & 0,20 & - & 2,85 & 0,97 & - & 15,91 \\
\hline CV \% & 22,9 & 39,4 & 20,1 & 7,7 & 17,6 & 54,2 & - & 19,1 & 9,0 & - & 17,8 \\
\hline $\begin{array}{l}\text { Referência } \\
\text { CETESB } \\
(\mathbf{2 0 0 5 )}\end{array}$ & 3,5 & 75 & $<0,5$ & 40 & 35 & 0,05 & $<4$ & 13 & 17 & 0,25 & 60 \\
\hline $\begin{array}{l}\text { Teor de } \\
\text { Prevenção } \\
\text { Resol. } \\
420 / 2009 \\
\text { CONAMA }\end{array}$ & 15 & 150 & 1,3 & 75 & 60 & 0,5 & 30 & 30 & 72 & 5 & 300 \\
\hline $\begin{array}{l}\text { Teor de } \\
\text { Investig./ } \\
\text { Agrícola } \\
\text { Resol. } \\
\text { 420/2009 } \\
\text { CONAMA }\end{array}$ & 35 & 300 & 3 & 150 & 200 & 12 & 50 & 70 & 180 & - & 450 \\
\hline \multicolumn{12}{|c|}{ Análise conjunta dos experimentos } \\
\hline Teste F p/ T & $0,56^{\mathrm{NS}}$ & $0,47^{\mathrm{NS}}$ & $0,83^{\mathrm{NS}}$ & $5,13^{\mathrm{NS}}$ & $3,50^{\mathrm{NS}}$ & $4,17^{\mathrm{NS}}$ & - & $3,88^{\mathrm{NS}}$ & $51,21 * *$ & - & $250,61 * *$ \\
\hline Teste F p/ E & $148,94 * *$ & $102,49 * *$ & $172,31 * *$ & $250,91 * *$ & $925,21 * *$ & $65,52 * *$ & - & $181,61 * *$ & $79,75 * *$ & - & $3480,67 * *$ \\
\hline $\begin{array}{l}\text { Teste F p/ } \\
\text { T x E }\end{array}$ & $0,27^{\mathrm{NS}}$ & $2,42^{\mathrm{NS}}$ & $2,91^{\mathrm{NS}}$ & $2,76^{\mathrm{NS}}$ & $1,11^{\mathrm{NS}}$ & $0,22^{\mathrm{NS}}$ & - & $1,07^{\mathrm{NS}}$ & $0,28^{\mathrm{NS}}$ & - & $0,07^{\mathrm{NS}}$ \\
\hline
\end{tabular}

$\mathrm{CV}=$ coeficiente de variação; $\mathrm{DMS}=$ diferença mínima significativa; $\mathrm{E}=$ experimentos; $\mathrm{T}=$ tratamentos; ${ }^{*}$ ) Médias seguidas de mesma letra, em coluna, não diferem entre si ao nível de $5 \%$ de probabilidade, pelo teste de Tukey, ${ }^{*}, * * \mathrm{e}^{\mathrm{NS}}$ - significativo ao nível de $5 \%(\mathrm{P}<0,05), 1 \%(\mathrm{P}<0,01)$ e $(\mathrm{P}>0,05)$ não significativo, respectivamente.

Fonte: Elaboração dos autores. 
Tabela 8. Quantidades de ETs adicionados aos solos através da aplicação de LE no ciclo agrícola 2009/2010 (13º ano).

\begin{tabular}{|c|c|c|c|c|c|c|c|c|c|c|}
\hline Tratamentos & \multicolumn{10}{|c|}{ Elementos traço } \\
\hline & As & $\mathbf{B a}$ & $\mathbf{C d}$ & $\mathrm{Cr}$ & $\mathbf{C u}$ & $\mathrm{Hg}$ & Mo & $\mathbf{N i}$ & $\mathbf{P b}$ & $\mathbf{Z n}$ \\
\hline t de LE ha ${ }^{-1}$ & \multicolumn{10}{|c|}{$\mathrm{kg} \mathrm{ha}^{-1}$} \\
\hline T 5 & 0,033 & 11,194 & 0,025 & 3,355 & 3,147 & 0,022 & 0,021 & 1,104 & 0,315 & 6,653 \\
\hline T 10 & 0,067 & 22,388 & 0,051 & 6,711 & 6,293 & 0,044 & 0,042 & 2,208 & 0,631 & 13,305 \\
\hline T 20 & 0,134 & 44,777 & 0,102 & 13,422 & 12,587 & 0,088 & 0,084 & 4,417 & 1,262 & 26,611 \\
\hline
\end{tabular}

Fonte: Elaboração dos autores.

Para o LVd, o primeiro elemento químico a atingir o limite crítico de investigação é o $\mathrm{Cr}$. Com teores de ETs iguais ou maiores que o VI no solo, a matriz ambiental passa a ter riscos potenciais diretos e indiretos à saúde humana, considerando um cenário de exposição padronizado (agrícola, residencial ou industrial), admitindo-se que os valores propostos nas normas sejam adequados e seguros para solos sob clima tropical.

A retenção dos ETs presentes no LE pelos solos é atribuída à forte sorção ou coprecipitação com óxidos de $\mathrm{Mn}$ e $\mathrm{Fe}$, nos minerais coloidais argilosos do solo e matéria orgânica, que os mantém em formas relativamente indisponíveis por longo período de tempo (McGRATH; CEGERRA, 1992). Entretanto, dentre outros pesquisadores, McBride (1995) argumenta que os ETs adicionados à matéria orgânica podem ser liberados, quando esta é mineralizada, potencialmente permitindo o movimento através do perfil do solo e maior biodisponibilidade.

São escassos os estudos de aplicação de LE em solos brasileiros de longa duração. Avaliar o comportamento dos ETs em condições de campo, em pesquisas de longo prazo adquire relevância, principalmente, na busca do efeito dinâmico desses elementos químicos que foram incorporados aos solos de forma antrópica através da aplicação do LE. São esses experimentos que fornecem subsídios na elaboração de normativas para a disposição adequada do LE em solos.

\section{Conclusões}

1. Após 13 aplicações anuais sucessivas de LE no LVef e LVd, os maiores teores dos ETs foram encontrados no LVef. Porém, e ainda não atingiram o valor de investigação (VI) agrícola da resolução 420/2009 do CONAMA.

2. Persistindo a atual taxa de aplicação de LE e teores médios dos ETs incorporados aos solos, espera-se que os elementos químicos $\mathrm{Ba}, \mathrm{Cd}, \mathrm{Cr}, \mathrm{Cu}$, $\mathrm{Ni}$ e $\mathrm{Zn}$ sejam os primeiros elementos a atingirem o VI no LVef.

\section{Agradecimentos}

Ao suporte financeiro fornecido pela CAPES/ UTFPR através do programa PIQDTec.

\section{Referências}

ANDRADE, M. G. Elementos-traço $\mathrm{As}, \mathrm{Ba}, \mathrm{Cd}, \mathrm{Cr}, \mathrm{Cu}$, $\mathrm{Hg}, \mathrm{Mo}, \mathrm{Ni}, \mathrm{Pb}$, Se e Zn em latossolos e plantas de milho após treze aplicações anuais de lodo de esgoto. 2011. Tese (Doutorado em Agronomia/Ciência do Solo) Universidade Estadual Paulista Júlio de Mesquita Filho, Jaboticabal.

BARBOSA, J. C.; MALDONADO JÚNIOR, W. AgroEstat: sistema para análises estatísticas de ensaios agronômicos. Versão 1.0. Jaboticabal: Unesp, 2010.

BERGKVIST， P.; JARVIS， N.; BERGGREN， D.; CARLGREN, K. Long-term effects of sewage sludge applications on soil properties, cadmium availability and distribution in arable soil. Agriculture, Ecosystems and Environment, Amsterdam, v. 97, n. 1, p. 167-179, 2003. 
BETTINELLI, M.; BEONE, G. M.; SPEZIA, S.; BAFFI, C. Determination of heavy metals in soils and sediments by microwaveassisted digestion and inductively coupled plasma optical emission spectrometry analysis. Analytica Chimica Acta, Oxford, v. 424, n. 2, p. 289-296, 2000.

BIZARRO, V. G.; MEURER, E. J.; TATSCH, F. R. P. Teor de cádmio em fertilizantes fosfatados comercializados no Brasil. Ciência Rural, Santa Maria, v. 38, n. 1, p. 247250, 2008.

CAMPOS, M. L.; SILVA, F. N.; FURTINI NETO, A. E.; GUILHERME, L. R. G.; MARQUES, J. J.; ANTUNES, A. S. Determinação de cádmio, cobre, cromo, níquel, chumbo e zinco em fosfatos de rocha. Pesquisa Agropecuária Brasileira, Brasília, v. 40, n. 4, p. 361-367, 2005.

CHEN, M.; MA, L. Q. Comparison of three aqua regia digestion methods for twenty Florida soils. Soil Science Society of America, Madison, v. 65, n. 2, p. 491-499, 2001.

COMPANHIA AMBIENTAL DO ESTADO DE SÃO PAULO - CETESB. Decisão de diretoria $n^{\circ}$ 195-2005 para valores orientadores para solos e águas subterrâneas no Estado de São Paulo. São Paulo: CETESB, 2005.

CONSELHO NACIONAL DO MEIO AMBIENTE CONAMA. Resolução 375, Critérios e procedimentos para o uso agrícola de lodos de esgoto gerados em estações de tratamento de esgoto sanitário e seus produtos derivados. Diário Oficial [da] União, Brasília, DF, 29 de ago. 2006. 32 p.

. Resolução 420, Critérios e valores orientadores de qualidade do solo quanto à presença de substâncias químicas e estabelece diretrizes para o gerenciamento ambiental de áreas contaminadas por essas substâncias em decorrência de atividades antrópicas. Diário Oficial [da] União, Brasília, DF, 28 dez. 2009. 16 p.

COVElO, E. F.; VEGA, F. A.; ANDRADE, M. L. Competitive sorption and desorption of heavy metals by individual soil components. Journal of Hazardous Materials, Amsterdam, v. 140, n. 1, p. 308-315, 2007.

KASHEM, M. A.; SINGH, B. R.; KAWAI, S. Mobility and distribution of cadmium, nickel and zinc in contaminated soil profiles from Bangladesh. Nutrient Cycling in Agroecosystems, Amsterdam, v. 77, n. 2, p. 187-198, 2007.

KIEKENS, L.; COTTENIE, A. Principles of investigations on the mobility and plant uptake of heavy metals. In: LESCHBER, R.; DAVIS, R. D.; L'HERMITÉ, P. Chemical methods for assessing bio-available metals in sludges and soils. London: Commission of the European Communities, Elsevier, 1985. p. 32-41.
LEMLY, A. D. Aquatic selenium pollution is a global environmental safety issue. Ecotoxicology and Environmental Safety, New York, v. 59, n. 1, p. 44-56, 2004.

McBRIDE, M. B. Toxic metal accumulation from agricultural use of sludge: Are USEPA regulations protective? Journal of Environmental Quality, Madison, v. 24, n. 1, p. 5-18, 1995.

McBRIDE, M. B.; SPIERS, G. Trace elements content of selected fertilizers and dairy manures as determined by ICP-MS. Communications in Soil Science and Plant Analysis, New York, v. 32, n. 1-2, p. 139-156. 2001.

McGRATH, S. P.; CEGERRA, J. Chemical extractability of heavy metals during and after long-term applications of sewage sludge to soil. Journal Soil Science, Chichester, v. 43, n. 2, p. 313-321, 1992.

MELO, V. P.; BEUTLER, A. N.; SOUZA, Z. M.; CENTURION, J. F.; MELO, W. J. Atributos físicos de Latossolos adubados durante cinco anos com biossólido. Pesquisa Agropecuária Brasileira, Brasília, v. 39, n. 1, p. 67-72, 2004.

MELO, W. J.; MARQUES, M. O. Potencial do lodo de esgoto como fonte de nutrientes para as plantas. In: BETIOL, W.; CAMARGO, O. A. (Ed.). Impacto ambiental do uso agrícola do lodo de esgoto. Jaguariúna: EMBRAPA Meio Ambiente, 2000. 312 p.

MENDES, A. M. S.; DUDA, G. P.; NASCIMENTO, C. W. A.; SILVA, M. O. Bioavailability of cadmium and lead in a soil amended with phosphorus fertilizers. Scientia Agricola, Piracicaba, v. 63, n. 4, p. 328-332, 2006.

MERLINO, L. C. S.; MELO, W. J.; MACEDO, F. G.; GUEDES, A. C. T. P.; RIBEIRO, M. H.; MELO, V. P.; MELO, G. M. P. Bário, cádmio, cromo e chumbo em plantas de milho e em latossolo após onze aplicações anuais de lodo de esgoto. Revista Brasileira de Ciência do Solo, Viçosa, MG, v. 34, n. 6, p. 2031-2039, 2010.

MINISTÉRIO DA AGRICULTURA, PECUÁRIA E ABASTECIMENTO - MAPA. Instrução normativa $\mathrm{n}^{\circ}$ 27. Diário Oficial [da] União, Brasília, 05 de jun. 2006.

NOGUEIRA, T. A. R.; OLIVEIRA, L. R.; MELO, W. J.; FONSECA, I. M.; MELO, G. M. P.; MELO, V. P.; MARQUES, M. O. Cádmio, cromo, chumbo e zinco em plantas de milho e em latossolo após nove aplicações anuais de lodo de esgoto. Revista Brasileira de Ciência do Solo, Viçosa, MG, v. 32, n. 5, p. 2195-2207, 2008.

OLIVEIRA, F. C.; MATTIAZZO, M. E. Mobilidade de metais pesados em um Latossolo Amarelo Distrófico tratado com lodo de esgoto e cultivado com cana-deaçúcar. Scientia Agricola, Piracicaba, v. 58, n. 4, p.807812, 2001. 
OLIVEIRA, K. W.; MELO, W. J.; PEREIRA, G. T.; MELO, V. P.; MELO, G. M. P. Heavy metals in oxisols amended with biosolids and cropped with maize in a long-term experiment. Scientia Agricola, Piracicaba, v. 62, n. 4, p. 381-388, 2005.

RAIJ, B. van; CANTARELLA, H. Milho. In: RAIJ, B. van; CANTARELLA, H.; QUAGGIO, J. A.; FURLANI,

A. M. C. Recomendação de adubação e calagem para $o$ Estado de São Paulo. 2. ed. Campinas: Instituto Agronômico, 1997. p. 56-59. (Boletim técnico, 100).

RAVEN, K. P.; LOEPPERT, R. H. Trace element composition of fertilizers and soil amendments. Journal of Environmental Quality, Madison, v. 26, n. 2, p. 551557, 1997.

RIEUWERTS, J. S.; ASHNORE, M. R.; FARAGO, M. E.; THORNTON, I. The influence of soil characteristics on the extractability of $\mathrm{Cd}, \mathrm{Pb}$ and $\mathrm{Zn}$ in upland and moorland soils. Science of the Total Environment, New York, v. 366, n. 2, p. 64-875, 2006.

SALVADOR-BLANES, S.; CORNU, S.; BOURENNANE, H.; KING, D. Controls of the spatial variability of $\mathrm{Cr}$ concentration in topsoils of a central French landscape. Geoderma, Amsterdam, v. 132, n. 1, p. 143-157, 2006.
SANDRONI, V.; SMITH, C. M. M. Microwave digestion of sludge, soil and sediment samples for metal analysis by inductively coupled plasma-atomic emission spectrometry. Analytica Chimica Acta, Oxford, v. 468, n. 2, p. 335-344, 2002.

SANTOS, E. J.; HERRMANN, A. B.; FRESCURA, V. L. A.; CURTIUS, A. J. Simultaneous determination of $\mathrm{As}, \mathrm{Hg}, \mathrm{Sb}, \mathrm{Se}$ and $\mathrm{Sn}$ in sediments by slurry sampling axial view inductively coupled plasma optical emission spectrometry using on-line chemical vapor generation with internal standardization. Journal of Analytical Atomic Spectrometry, London, v. 20, n. 6, p. 538-543, 2005.

VIEIRA, E. C.; KAMOGAWA, M. Y.; LEMOS, S. G.; NÓBREGA, J. A.; NOBREGA, A. R. A. Decomposição de amostras de solos assistida por radiação microondas: estratégia para evitar a formação de fluoretos insolúveis. Revista Brasileira de Ciência do Solo, Viçosa, MG, v. 29, n. 4, p. 547-553, 2005.

VOLPE, C. A.; CUNHA, A. R. Dados meteorológicos de Jaboticabal no período de 1971-2000. In: FÓRUM DE ESTUDOS DOS PROBLEMAS REFERENTES ÀS MUDANÇAS MESOCLIMÁTICAS NO MUNICÍPIO DE JABOTICABAL, 1., Jaboticabal, 2008. Relatório final... Jaboticabal, Comissão de Assuntos Relevantes da Câmara Municipal de Jaboticabal, 2008. CD-ROM. 